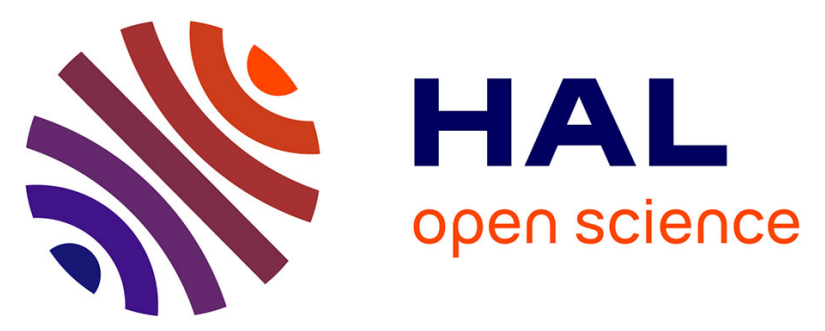

\title{
Experimental and theoretical Study of morphological and charging properties of truncated octahedron and cubic ceria nanoparticles: Implications for biomedical applications
}

Klemen Bohinc, Karla Korade, Katarina Jerin, Nikolina Lešić, Marijana

Đaković, Goran Dražić, Jean-François Dufrêche, Davor Kovačević

\section{To cite this version:}

Klemen Bohinc, Karla Korade, Katarina Jerin, Nikolina Lešić, Marijana Đaković, et al.. Experimental and theoretical Study of morphological and charging properties of truncated octahedron and cubic ceria nanoparticles: Implications for biomedical applications. ACS Applied Nano Materials, 2021, 4 (2), pp.1434-1444. 10.1021/acsanm.0c02960 . hal-03120543

\section{HAL Id: hal-03120543 \\ https://hal.umontpellier.fr/hal-03120543}

Submitted on 3 Sep 2021

HAL is a multi-disciplinary open access archive for the deposit and dissemination of scientific research documents, whether they are published or not. The documents may come from teaching and research institutions in France or abroad, or from public or private research centers.
L'archive ouverte pluridisciplinaire HAL, est destinée au dépôt et à la diffusion de documents scientifiques de niveau recherche, publiés ou non, émanant des établissements d'enseignement et de recherche français ou étrangers, des laboratoires publics ou privés. 


\title{
Experimental and Theoretical Study of Morphological and Charging Properties of Truncated Octahedron and Cubic Ceria Nanoparticles: Implications for Biomedical Applications
}

\author{
Klemen Bohinc,* Karla Korade, Katarina Jerin, Nikolina Lešić, Marijana Đaković, Goran Dražić, \\ Jean-François Dufrêche, and Davor Kovačević**
}

Cite This: ACS Appl. Nano Mater. 2021, 4, 1434-1444

Read Online

ACCESS | Lلll Metrics \& More | 回 Article Recommendations | sl supporting Information

ABSTRACT: Ceria $\left(\mathrm{CeO}_{2}\right)$ nanoparticles are known to be very often used in various applications from biomedicine to fuel cells. To optimize the applications, detailed information about the physicochemical properties such as size, shape, and charge of nanoparticles should be available. Therefore, in our study we performed a systematic study of ceria nanoparticles ranging from synthesis to comprehensive experimental and theoretical characterization. We synthesized ceria nanoparticles using two synthesis paths which led to the formation of two types of ceria nanoparticles. The structure and charging properties of both types of ceria nanoparticles were studied by using X-ray powder diffraction (XRD), high-resolution transmission electron micros-

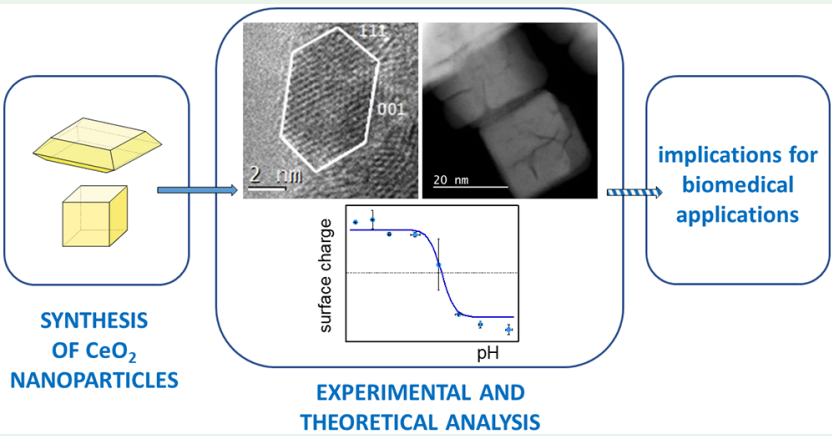
copy (HR-TEM), particle charge detector (PCD) for surface charge density, and a ZetaPlus instrument for electrophoretic mobility measurements. The results suggested that in the case where hydrolysis of $\mathrm{Ce}\left(\mathrm{NO}_{3}\right)_{3}$ at room temperature was applied nanoparticles with morphology close to a spherical, more exactly truncated octahedron were synthesized. On the other hand, nanoparticles obtained by hydrothermal synthesis had characteristic cube-like morphology. Finally, for more complete understanding and interpretation of the studied system, we prepared a theoretical model based on the classical density functional theory for electrolyte solutions coupled with the surface charge regulation via the law of mass action. Even without using fitting parameters, the theory adequately describes the experimental data. All the results obtained in our study could serve as a basis for obtaining tuned and engineered ceria nanoparticles with optimized physicochemical properties which could lead to the improved applications of the nanotechnology in the biomedical research.

KEYWORDS: cerium oxide, truncated octahedron nanoparticles, cubic nanoparticles, surface charge, HR-TEM, isoelectric point, density functional theory

\section{INTRODUCTION}

In recent years we have witnessed rapid advances in the field of synthesis and applications of cerium oxide $\left(\mathrm{CeO}_{2}\right.$, ceria) nanoparticles (shortened $\mathrm{CeO}_{2} \mathrm{NPs}$ ). That is attributed to their specific physicochemical properties like nano size, good crystallinity, morphology, and charge. These properties make $\mathrm{CeO}_{2}$ NPs suitable for potential applications in biomedicine, catalysis, fuel cells, and development of antibacterial coatings. ${ }^{1}$

$\mathrm{CeO}_{2}$ NPs are considered as very good catalysts because of their redox behavior and cerium's redox state. ${ }^{2,3}$ Namely, they are composed of $\mathrm{Ce}^{3+}$ and $\mathrm{Ce}^{4+}$, the latter contributing to the stronger catalase mimetic activity. ${ }^{4}$ Besides the charge, the shape and the size of nanoparticles also strongly impact the catalytic activity. ${ }^{5,6}$

Various valuable properties of $\mathrm{CeO}_{2}$ NP's are also essential for their effective biomedical applications. For example, their antioxidant activity ${ }^{7}$ and biocompatibility ${ }^{1}$ are used to prevent diseases of the central nervous system. $\mathrm{CeO}_{2}$ NPs shaped as cubes and coated with chitin form stable colloids, which reduce or eliminate toxic properties ${ }^{8}$ and have beneficial effects on healing open wounds. Furthermore, the application of $\mathrm{CeO}_{2}$ NPs in the field of biomedicine has been recently extended to brain diseases, including ischemic stroke, intracerebral and subarachnoid hemorrhage, Parkinsonian syndrome, and Alzheimer's disease. The reason is that the $\mathrm{CeO}_{2} \mathrm{NPs}$ exhibit excellent reactive oxygen species scavenging activity in biological environments, mimicking superoxide dismutase

Received: November 5, 2020

Accepted: January 11, 2021

Published: January 20, 2021 

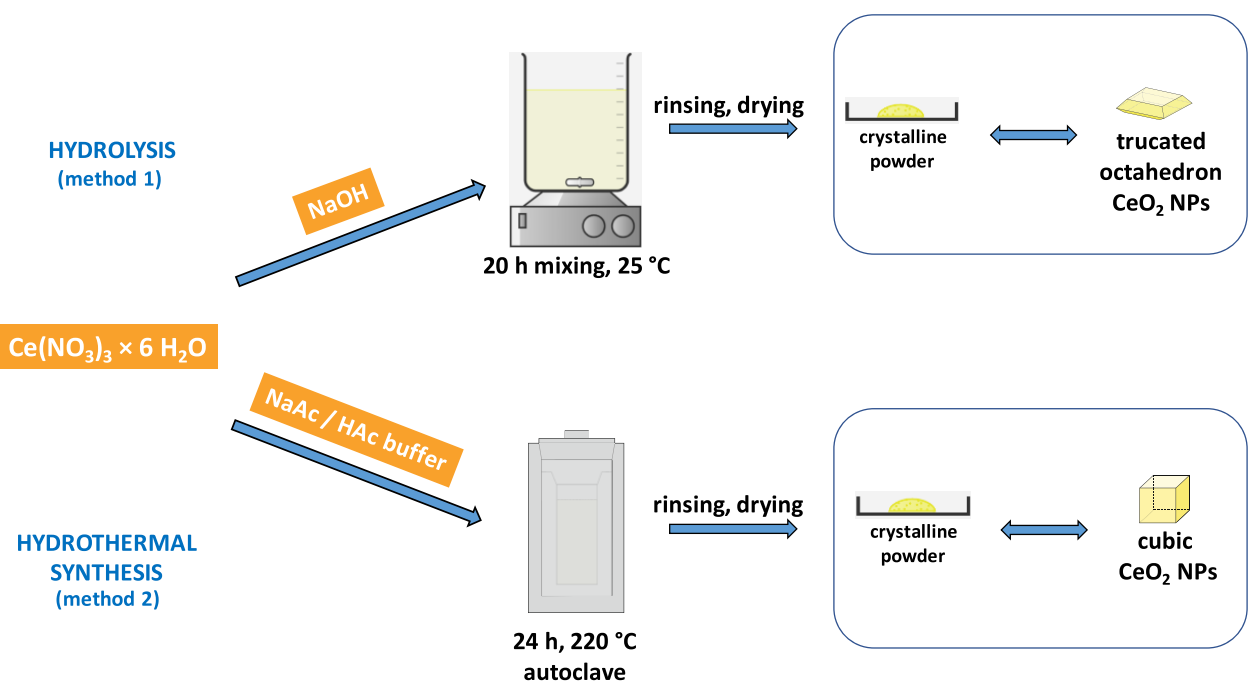

Figure 1. Illustrated scheme of methods used for the synthesis of two types of ceria nanoparticles.

and catalase. ${ }^{9}$ Recently, it was suggested ${ }^{10}$ that $\mathrm{CeO}_{2} \mathrm{NPs}$, because of their promising anti-inflammatory, antioxidant, and antifibrotic properties, could also serve as an attractive instrument in the fight against the SARS-CoV-2 as well as the related systemic complications.

For optimized applications of nanoparticles in various fields of research, detailed and reliable information about their morphological and charging properties is needed. That is especially important in the case of ceria nanoparticles because of their plentiful applications. The importance of $\mathrm{CeO}_{2} \mathrm{NPs}$ lies in their biocompatibility and relatively low health risks ${ }^{11,12}$ which make them very important for biomedical applications. For example, it was shown ${ }^{11}$ that $\mathrm{CeO}_{2} \mathrm{NPs}$ caused, even at the highest dose, very little inflammatory response in human aortic endothelial cells, making them rather benign in comparison to, for example, $\mathrm{Y}_{2} \mathrm{O}_{3}$ and $\mathrm{ZnO}$ nanoparticles. On the other hand, caution is advised since it was recently shown that cerium dioxide nanoparticles affect in vitro fertilization in mice. ${ }^{13}$ Even very low concentrations of $\mathrm{CeO}_{2}$ NPs could induce DNA damage (however, no loss of vitality was reported) in human spermatozoa. ${ }^{14}$ Pulido-Reyes and coworkers $^{15}$ found that the possible toxicity of cerium oxide nanoparticles depends on the percentage of $\mathrm{Ce}^{3+}$ at the surface of nanoparticles.

$\mathrm{CeO}_{2} \mathrm{NPs}$ are used in the development of novel antibacterial coatings, mainly for Gram-negative bacteria and fungi. ${ }^{16-18}$ At the acidic $\mathrm{pH}$ the mechanism is favored through the electrostatic interaction where the positively charged $\mathrm{CeO}_{2}$ NP adsorbs to the negatively charged bacterial surface. During the adsorption process a valence change occurs on the $\mathrm{CeO}_{2}$ NP surface in which $\mathrm{Ce}^{4+}$ is converted to $\mathrm{Ce}^{3+}$, and the result is oxidative stress on lipids and/or proteins in the bacterial plasma membrane.

Understanding surface chemistry of ceria nanoparticles is very important not only from a fundamental point of view but also for tuning various application possibilities to obtain the optimal results. It was shown for example that at the nanoregime the oxygen storage ability of ceria is strongly dependent on its size. ${ }^{19}$ Moreover, nanosized cerium oxide is a good candidate, acting as a heterogeneous catalyst, for the degradation of organophosphorus compounds. In that sense, it was shown that both specific surface area and crystal faces of the nanoparticles influence that process. ${ }^{20}$ Also, the stability of the dispersion of nanoparticles, especially at physiological $\mathrm{pH}$, is important. We showed recently ${ }^{21}$ that the Ohshima model could be applied for studying ceria nanoparticle/strongly charged polyelectrolyte solution interface and that the obtained results could serve as a basis for further tailored applications of polyelectrolytes as stabilizing agents for nanoparticles.

It is important to stress here that the crystal morphology could also be correlated to various material properties such as magnetism, electronic and optical properties, and so on. For example, Santiago and co-workers used a combined experimental and theoretical approach to elucidate the structuralproperty relationship of $\mathrm{CuMnO}_{2}$ nanoparticles from different morphologies. $^{22-25}$

The morphology and size of nanoparticles can be studied by various methods. ${ }^{26,27}$ One of the most accurate methods for quantitative analysis of nanoparticles is HR-TEM coupled with ER electron energy-loss spectroscopy (EELS) and energydispersive X-ray spectroscopy (EDXS). X-ray diffraction (XRD) is also one of the most extensively used techniques for the characterization of NPs. Generally, XRD provides information about the crystalline structure, nature of the phase, lattice parameters, and crystalline grain size. The surface charge density can be determined by polyelectrolyte titration with streaming potential measurement. ${ }^{28}$ From electrophoretic mobility measurements, the isoelectric point can be determined as well as the mobilities of uncoated and coated nanoparticles as a function of $\mathrm{pH}$.

It is well-known that for obtaining the complete picture of the studied systems the holistic approach which combines experiments and theoretical results is required. From the theoretical point of view for monovalent ions and weakly charged macroions, Poisson-Boltzmann (PB) theory makes correct predictions for ion concentration around charged surfaces. ${ }^{29,30}$ In PB theory the ions are treated as point-like embedded in a continuum electrolyte solution. The charge on surfaces is continuously smeared. In the past there were many attempts to improve PB theory. In one of them the full PB was upgraded by treating the fraction of dissociated ionizable surface groups as a self-consistent functional of the electrostatic potential. $^{31}$ Recently, PB theory was applied for nanotubular structures, where the charge regulations via the law of mass 
action was considered. ${ }^{32}$ This is especially important to understand and interpret the experimental data.

Finally, to make a long story short, we decided to systematically study the surface properties of ceria nanoparticles and apply a combined approach based on experimental and theoretical investigations. For that purpose, we synthesized two types of $\mathrm{CeO}_{2} \mathrm{NPs}$ (Figure 1) and used several experimental methods to characterize them systematically. Chemical composition was analyzed with X-ray powder diffraction, and additionally, the size of the particles was estimated with Scherer's equation. The size and morphology of the particles were investigated with HR-TEM. Additionally, the mobility of particles in suspensions of different ionic strengths and supporting cations was measured to determine the charging properties of the ceria particles in suspensions. The influence of two alkali cations, sodium and cesium, was investigated. Finally, the surface charge density of the particles was experimentally obtained by polyelectrolyte neutralization and compared with the theoretical predictions.

\section{EXPERIMENTAL SECTION}

2.1. Synthesis of Ceria Nanoparticles. Cerium oxide nanoparticles were in the first case (Figure 1, method 1) synthesized by hydrolysis of cerium(III) nitrate hexahydrate $\left(\mathrm{Ce}\left(\mathrm{NO}_{3}\right)_{3} \cdot 6 \mathrm{H}_{2} \mathrm{O}\right.$; obtained by Fluka, p.a. $>99.0 \%)$ at room temperature according to the procedure described in the literature. ${ }^{33} \mathrm{NaOH}$ aqueous solution $\left(V=125 \mathrm{~mL}, c=1.0 \mathrm{~mol} \mathrm{dm}{ }^{-3}\right.$, Titrisol, Merck) was added to cerium(III) nitrate aqueous solution $\left(V=5 \mathrm{~L}, \gamma=2.5 \mathrm{~g} \mathrm{dm}^{-3}\right)$ under constant stirring. The obtained suspension was stirred continuously for $20 \mathrm{~h}$ at room temperature, which led to the change in the color of suspension from violet to yellow. The precipitate was purified by intensive rinsing with deionized water until the conductivity of the supernatant reached the conductivity of deionized water. Finally, the particles were dried at $80{ }^{\circ} \mathrm{C}$ and stored in a glass bottle at room temperature.

For the synthesis of cerium oxide nanoparticles using method 2 (Figure 1), hydrothermal synthesis was used. ${ }^{8}$ Acetate buffer was prepared by dissolution of sodium acetate $\left(m\left(\mathrm{CH}_{3} \mathrm{COONa}\right)=10 \mathrm{~g}\right.$, Gram-Mol, p.a. $99.5 \%)$ in concentrated acetic acid $\left(\mathrm{V}\left(\mathrm{CH}_{3} \mathrm{COOH}\right.\right.$, conc.) $=10 \mathrm{~mL}$, Gram-Mol, p.a. $99 \%)$ and diluted with $50 \mathrm{~mL}$ water. Cerium(III) nitrate hexahydrate $\left(n\left(\mathrm{Ce}\left(\mathrm{NO}_{3}\right)_{3} \cdot 6 \mathrm{H}_{2} \mathrm{O}=5 \times 10^{-3}\right.\right.$ $\mathrm{mol}$ ) was added to the buffer, and the solution was diluted to $85 \mathrm{~mL}$ and stirred for $30 \mathrm{~min}$. The solution was then transferred into a Teflon-lined stainless steel autoclave (using $85 \%$ of autoclave capacity) and heated to $220{ }^{\circ} \mathrm{C}$ for $24 \mathrm{~h}$. The obtained nanoparticles were then rinsed with deionized water, centrifuged, and resuspended until the $\mathrm{pH}$ and conductivity of the supernatant remained constant.

2.2. Characterization of Ceria Nanoparticles. Ceria nanoparticles were characterized by various experimental methods. X-ray powder diffraction (XRD), transmission electron microscopy (TEM), and electrophoretic light scattering (ELS) as well as surface charge measurements were used.

$\mathrm{X}$-ray powder diffraction experiments were performed on Philips PW 1850 diffractometer in the Bragg-Brentano geometry employing the $\mathrm{Cu} \mathrm{K} \alpha$ radiation $(\lambda=1.542 \AA)$, operated at $40 \mathrm{kV}$ and $30 \mathrm{~mA}$. The patterns were collected in the angle region between $20^{\circ}$ and $65^{\circ}$ $(2 \theta)$.

A JEOL ARM-200 CF probe Cs-corrected scanning transmission electron microscope, operated at $80 \mathrm{kV}$ and equipped with a dual EELS system (QuantumGIF, Gatan, USA), was used for the study of size, shape, crystallinity, and Ce valence state. High-resolution transmission electron microscopy, bright-field scanning transmission electron microscopy, and high-angle annular dark-field (HAADFSTEM) imaging techniques were used in the study.

Electrophoretic mobilities of the nanoparticles were determined by means of ZetaPlus instrument (Brookhaven Instruments Corporation) at $25{ }^{\circ} \mathrm{C}$.
The mass concentration of the suspension of $\mathrm{CeO}_{2} \mathrm{NPs}$ used for electrokinetic measurements was $\gamma=0.1 \mathrm{~g} \mathrm{dm}^{-3}$. The $\mathrm{pH}$ of the suspension was adjusted to the initial $\mathrm{pH}$ value $(\mathrm{pH}=3$ or $\mathrm{pH}=10)$ by the addition of $\mathrm{HNO}_{3}$ (Riedel-de-Häen) or $\mathrm{MOH}(\mathrm{M}=\mathrm{Na}$ or Cs (Sigma-Aldrich, p.a. 99\%)). Afterward, titrations were made in both directions, i.e., from the acidic region (starting from $\mathrm{pH}=3$ ) and from the basic region (starting from $\mathrm{pH}=10$ ), and the electrophoretic mobility was measured at various $\mathrm{pH}$ values. Each measurement (consisting of 10 measuring points) was repeated three times.

The surface charge of ceria nanoparticles was measured by using a Mütek particle charge detector (PCD-05). A suspension of spherical ceria nanoparticles was prepared by adding the appropriate amount of $\mathrm{CeO}_{2} \mathrm{NPs}\left(\gamma=0.1 \mathrm{~g} \mathrm{dm}^{-3}\right)$ into a solution containing both hydrochloric acid $\left(c(\mathrm{HCl})=0.001 \mathrm{~mol} \mathrm{dm}^{-3}\right.$, AVS Titrinorm $)$ and sodium chloride $\left(c(\mathrm{NaCl})=0.001 \mathrm{~mol} \mathrm{dm}^{-3}\right.$, Fluka, 99.5\%) prepared by mixing these two solutions. Therefore, the total ionic strength of the solution was $I_{\mathrm{c}}=2 \times 10^{-3} \mathrm{~mol} \mathrm{dm}{ }^{-3}$. The $\mathrm{pH}$ of the solution was $\mathrm{pH} \approx 3$. To obtain other $\mathrm{pH}$ values in the range between $\mathrm{pH}=2.5$ and $\mathrm{pH}=9$, hydrochloric acid $\left(c=0.1 \mathrm{~mol} \mathrm{dm}^{-3}\right)$ or sodium hydroxide solution $\left(c=0.1 \mathrm{~mol} \mathrm{dm}{ }^{-3}\right)$ was added. For all the points between $\mathrm{pH} \approx 3$ and $\mathrm{pH} \approx 7$, the ionic strength of the solution $\left(I_{\mathrm{c}}=2\right.$ $\times 10^{-3} \mathrm{~mol} \mathrm{dm}^{-3}$ ) was kept constant by adding $\mathrm{NaOH}$ since neutralization takes place, water is generated, and there is no change in ionic strength. Only for points below $\mathrm{pH} \approx 3$ (one point) and above $\mathrm{pH} \approx 7$ (two points) there is a slight change (increase) in ionic strength but almost negligible. The suspension was then put in an ultrasonic bath for $30 \mathrm{~min}$. The titrant (PSS (BTG) or PDADMAC (Sigma-Aldrich) solution; in both cases $c=5 \times 10^{-5} \mathrm{~mol} \mathrm{dm}^{-3}$ ) was chosen depending on the initial charge of the nanoparticles. The titrant solution was added in small fragments until the streaming potential was equal to $0 \mathrm{mV}$. Finally, the total charge per unit of mass was converted to charge per unit of length $\left(\mathrm{C} \mathrm{m}^{-1}\right)$ to enable the comparison with theoretical results.

2.3. Theory. For a better understanding and improved interpretation of the surface charge density dependence on $\mathrm{pH}$, we prepared a theoretical model based on the classical density functional theory for electrolyte solutions coupled with the surface charge regulation via the law of mass action. The Debye length of the system $(2.8 \mathrm{~nm})$ is small compared to the size of $\mathrm{CeO}_{2} \mathrm{NPs}$, and the planar geometry is a good approximation. So we consider charged surfaces in contact with an electrolyte solution composed of positively and negatively charged small ions embedded in an electrolyte with a given dielectric constant of $\varepsilon=78$. The grand canonical potential of our system can be written as

$$
\begin{gathered}
F\left[\phi(r), n_{i}(r)\right]=k T \int \sum_{i} z_{i} n_{i}(r) \phi(r) \mathrm{d} r^{3} \\
+k T \int \sum_{i} n_{i}(r)\left[\ln \frac{n_{i}(r)}{n_{i 0}}-1\right] \mathrm{d} r^{3}
\end{gathered}
$$

where $\phi$ is the electrostatic potential, $z_{i}$ are the valences of ions, $n_{i}(r)$ are one-body ion densities of the $i$ th type of ion, $\rho_{i 0}$ are their bulk values, and $k T$ is the thermal energy. The energy is integrated over the full space, $r$ being the coordinate perpendicular to the surface. The functional minimization of the grand canonical potential (1) delivers Boltzmann distributions

$$
\begin{aligned}
& n_{i}(r)=n_{0 i} \mathrm{e}^{-z_{i} \phi(r)} \\
& {\left[\mathrm{H}^{+}\right](r)=\left[\mathrm{H}^{+}\right]_{0} \mathrm{e}^{-\phi(r)}}
\end{aligned}
$$

where $\left[\mathrm{H}^{+}\right]_{0}$ is the bulk concentration of oxonium ions which determines the $\mathrm{pH}$ of the solution via $\mathrm{pH}=-\log \left[\mathrm{H}^{+}\right]_{0}$. These Boltzmann's distributions are the input for the Poisson equation leading to the Poisson-Boltzmann (PB) equation for reduced electrostatic potential $\phi$

$$
\frac{\mathrm{d}^{2} \phi(r)}{\mathrm{d} r^{2}}+\frac{\eta}{r} \frac{\mathrm{d} \phi(r)}{\mathrm{d} r}=-4 \pi l_{\mathrm{B}} \sum_{i} z_{i} n_{0 i} \mathrm{e}^{-z_{i} \phi(r)}
$$




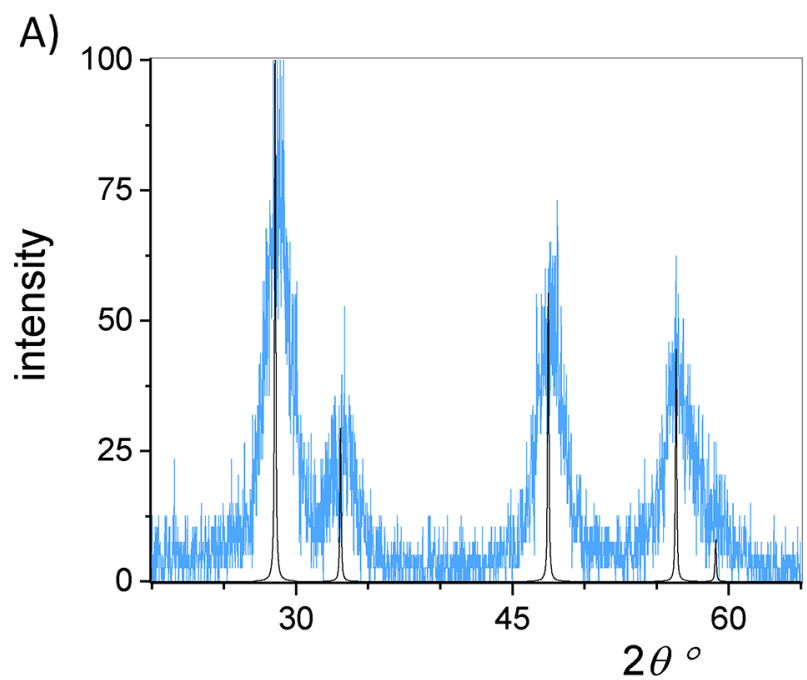

B)
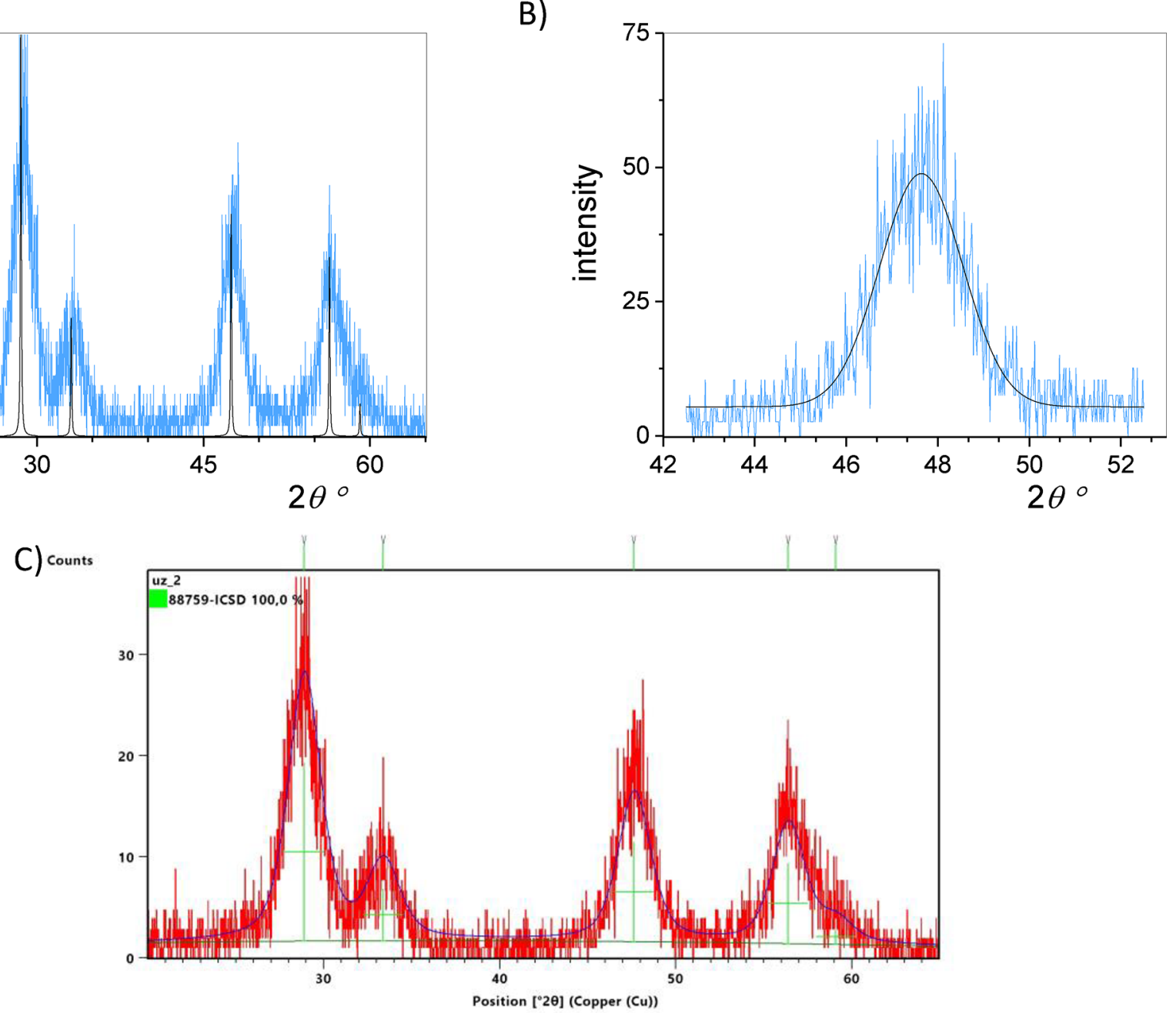

Figure 2. (A) Overlay of the XRD diffraction patterns of ceria nanoparticles synthesized by the method 1 (blue) and calculated $\mathrm{CeO}_{2}$ retrieved from the ICSD database (black line). (B) Diffraction maximum at $2 \theta=47.64^{\circ}$ approximated with the Gauss function to determine parameters for Scherrer's equation; $k=0.95, \lambda=0.1542 \mathrm{~nm}, \beta_{1 / 2}=2.12^{\circ}$, and $\theta_{\mathrm{m}}=23.82^{\circ}$. (C) Rietveld fit to PXRD pattern measured for sample of CeO synthesized by method 1 . The powder pattern was fitted by Rietveld refinement using the HighScore program, ${ }^{38}$ starting from the unit-cell parameters retrieved from ICSD.

where the parameter $\eta$ describes the geometry of the system and $r$ is the coordinate perpendicular to the nanoparticles surface. $l_{\mathrm{B}}$ is the Bjerrum length, $z_{i}$ is the valency of ions, and $n_{0 i}$ is the bulk ion concentration of the $i$ th species. The PB equation can be solved in accordance with two boundary conditions. The first boundary condition is equal to the electroneutrality of the system

$$
\left.\frac{\mathrm{d} \phi}{\mathrm{d} r}\right|_{\text {surf }}=\frac{-e \sigma}{\varepsilon \varepsilon_{0} k T} \text { and } \phi(\infty)=0
$$

where $\varepsilon_{0}$ is the permittivity of free space and $\sigma$ being the surface charge density

$$
\sigma=e \Gamma \sum_{i=1}^{2} z_{i} f_{i}
$$

where the surface site density $\Gamma=\left[\mathrm{Ce}_{2} \mathrm{O}^{-}\right]+\left[\mathrm{Ce}_{2} \mathrm{OH}^{+}\right]$is the sum of all equilibrium surface site concentrations, and $f_{i}$ is the fractional coverage which defines the ratio of the charged groups in the total number of sites on the surface. The second boundary condition fixes the electrostatic potential far from the nanoparticles surface

$$
\left.\phi\right|_{\text {inf }}=0
$$

The differential equation was solved analytically in a self-consistent manner and the following algebraic equation for surface per elementary charge $a=e / \sigma$ was obtained

$$
\frac{1}{a \Gamma}=\frac{-1+10^{2\left(\mathrm{pH}_{\mathrm{pzc}}-\mathrm{pH}\right)\left(\frac{1+a s-\sqrt{a^{2} s^{2}+1}}{1-a s+\sqrt{a^{2} s^{2}+1}}\right)^{4}}}{1+10^{2\left(\mathrm{pH}_{\mathrm{pzc}}-\mathrm{pH}\right)\left(\frac{1+a s-\sqrt{a^{2} s^{2}+1}}{1-a s+\sqrt{a^{2} s^{2}+1}}\right)^{4}}}
$$

where $s=\sqrt{2 n_{0} / \pi l_{\mathrm{B}}}$ and $\mathrm{pH}_{\mathrm{pzc}}$ is the $\mathrm{pH}$ in the point of zero charge.

The solutions are consistent with the molecular dynamics simulation. ${ }^{34,35}$ The details of the derivation are given in the Supporting Information.

\section{RESULTS AND DISCUSSION}

3.1. Ceria Nanoparticles Morphology: Truncated Octahedron vs Cubic Nanoparticles. The size, shape, morphology, and charging properties of nanoparticles play a crucial role in various possible applications. Therefore, the characterization of nanoparticles (NP) obtained by various synthesis paths is the prerogative for the optimal applications. In our study we synthesized $\mathrm{CeO}_{2} \mathrm{NPs}$ via two synthesis paths 

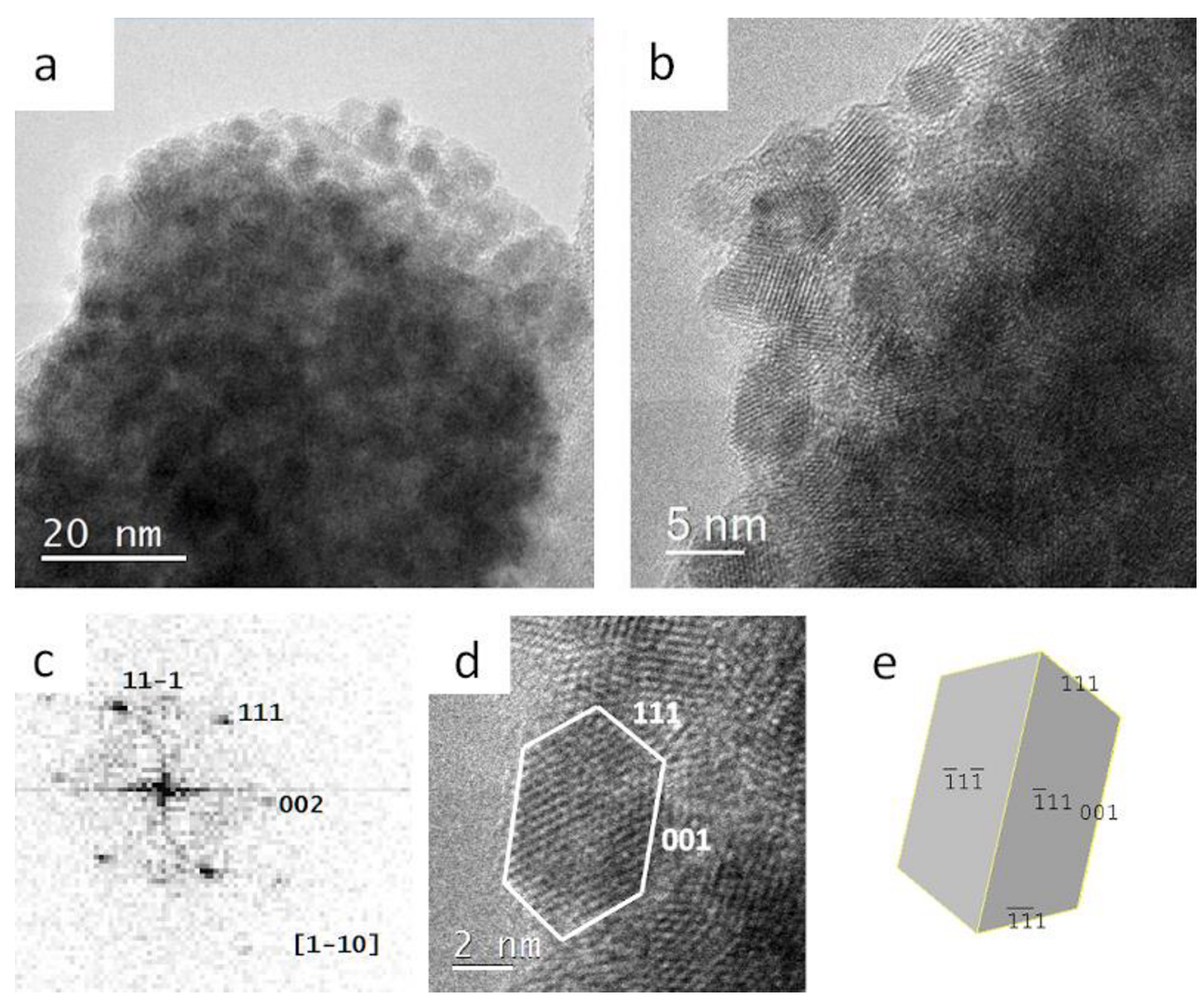

Figure 3. (a, b) TEM and HR-TEM images of $\mathrm{CeO}_{2}$ truncated octahedron nanoparticles in sample 1. (c) FFT of HR-TEM image (d) of a particle in the $[1-10]$ zone axis with labeled (111) and (001) terminal planes. (e) The corresponding truncated octahedron model that can explain the morphology of the particle.

that, according to the literature, ${ }^{8,33}$ should lead to the formation of nanospheres (method 1) and nanocubes (method 2).

The X-ray diffraction pattern of the ceria sample synthesized by method 1 is presented in Figure 2. The diffraction pattern was compared with the calculated one for $\mathrm{CeO}_{2}$ that was retrieved from the ICSD database. The Rietveld refinement confirmed that the sample is a pure, single phase of cerium(IV) oxide. The diffraction peaks are substantially broadened, reflecting small particle size. The calculated medium diameter of the ceria nanoparticles (nanocrystallite size) was estimated by using the Scherrer equation ${ }^{36,37}$ to be $D_{\mathrm{p}} \approx 5.3 \mathrm{~nm}(k=$ $\left.0.95 ; \lambda=0.1542 \mathrm{~nm} ; \beta_{1 / 2}=2.12^{\circ} ; \theta_{\mathrm{m}}=23.82^{\circ}\right)$.

Additionally, we analyzed ceria nanoparticles by means of transmission electron microscopy (HR-TEM). While XRD is being used for calculation of the average (nano)crystallite particle size by using the Scherrer formula, HR-TEM delivers the images from which information about the size and shape of nanoparticles is obtained. However, both measurement techniques have their own importance. Therefore, we used HR-TEM, as a very strong tool for characterization of nanoparticles, to determine the size and shape of synthesized nanoparticles, and from the shape and crystallographic orientation we were able to identify terminal planes in the crystals. In Figures $3 a$ and $3 b$ the TEM and HR-TEM images of particles agglomerates are shown where particles have morphology close to spherical.

We estimated that the diameter of particles was around 4 $\mathrm{nm}$. In some crystallites we were able to determine the zone axis, and from the position of the terminal planes we were able to do the $3 \mathrm{D}$ shape reconstruction. Figure $3 \mathrm{c}$ is the HR-TEM image of a particle with (111) and (001) terminal planes; Figure $3 \mathrm{~d}$ is the FFT of the image with labeled planes and in Figure $3 \mathrm{e}$ the corresponding truncated octahedron model. The presence of $\mathrm{Ce}^{4+}$ was confirmed from the spectra (Figure S4) obtained by electron energy loss spectroscopy (EELS) based on the shape, position, and intensity ratio of M5 and M4 white lines. Pre-edge line at the $\mathrm{O} \mathrm{K}$ edge and post-edge lines ( $\mathrm{Y}$ and $\mathrm{Y}^{\prime}$ line) at the M 4,5 edge are characteristic for $\mathrm{Ce}^{4+}$.

Because the shape of the nanoparticles is assumed to be one of the critical parameters regarding possible applications, we also synthesized ceria nanoparticles by method 2 (see the Experimental Section for details) that should lead to the formation of nanocubes. The specific surface area of that ceria sample was also determined by the multiple Brunauer, Emmett, and Teller (BET) method and was found to be $56.18 \pm 0.24 \mathrm{~m}^{2} \mathrm{~g}^{-1}$. Prior to the determination of the surface area, the sample was outgassed at $100{ }^{\circ} \mathrm{C}$ for $1 \mathrm{~h}$. In the case of the nanoparticles obtained by method 2 the powder XRD patterns also confirm that the chemical composition of the prepared sample is pure cerium oxide (Figure 4). Also, diffraction maxima are narrower than in the previous sample of cerium(IV) oxide nanoparticles, indicating somewhat larger crystallite particles in this sample. The mean nanoparticle diameter, which was calculated as for the nanoparticles synthesized by method 1 , was found to be $D_{\mathrm{p}} \approx 25.4 \mathrm{~nm}(k$ $=0.95, \lambda=0.1542 \mathrm{~nm}, \beta_{1 / 2}=0.361^{\circ}$, and $\left.\theta_{\mathrm{m}}=23.79^{\circ}\right)$.

As confirmed by the analysis of HR-TEM images, the nanoparticles prepared by method 2 have characteristic cubelike morphology which is shown in Figure 5. Their estimated size (edge length) is approximately $d \approx 23 \mathrm{~nm}$, making them, as expected, somewhat larger than the nanoparticles prepared 


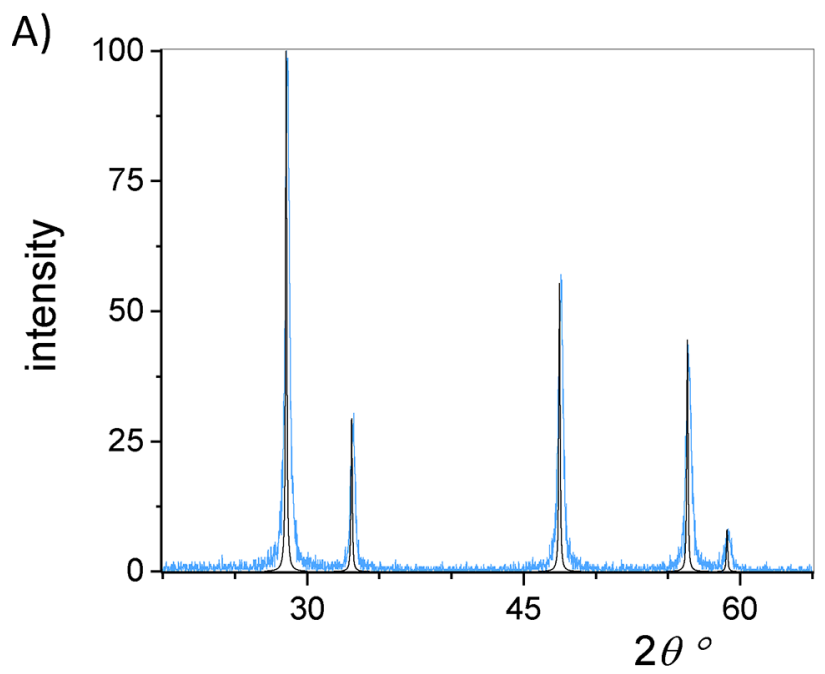

B)
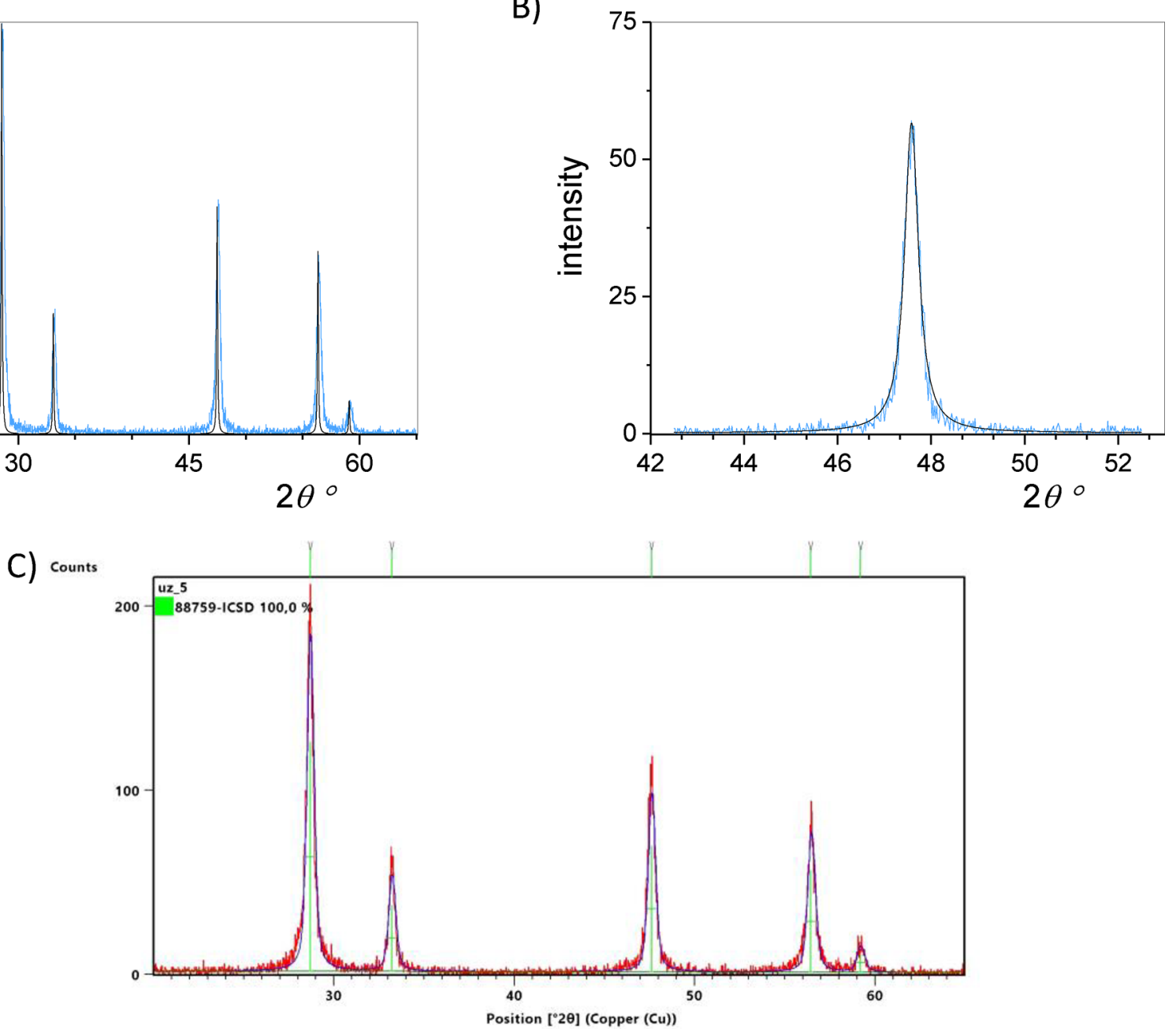

Figure 4. (A) Overlay of the XRD diffraction patterns of ceria nanoparticles synthesized by method 2 (blue) and calculated $\mathrm{CeO}_{2}$ retrieved from the ICSD database (black line). (B) Diffraction maximum at $2 \theta=47.7^{\circ}$ approximated with the Lorentz function to determine parameters for Scherrer's equation; $k=0.95, \lambda=0.1542 \mathrm{~nm}, \beta_{1 / 2}=0.361^{\circ}$, and $\theta_{\mathrm{m}}=23.79^{\circ}$. (C) Rietveld fit to PXRD pattern measured for sample of CeO synthesized by method 2 . The powder patterns were fitted by Rietveld refinement using HighScore, ${ }^{38}$ starting from the unit-cell parameters retrieved from ICSD.

by method 1 . In this morphology most of the terminal planes are of (001) type. In Figures 5d,e the crystal models corresponding to the nanoparticles shown in Figure $5 \mathrm{c}$ are shown: one model composed of $\mathrm{Ce}$ atoms and another with labeled plane indices.

As shown in the case of truncated octahedron ceria nanoparticles, in the case of cubic ceria nanoparticles the presence of $\mathrm{Ce}^{4+}$ was also confirmed from the spectra obtained by electron energy loss spectroscopy (EELS), as presented in Figure S5, based on the shape, position, and intensity ratio of M5 and M4 white lines.

From the results presented in Figures 3 and 5 it could be concluded that method 1 leads to the formation of truncated octahedron nanoparticles (bounded with (111) and (100) planes) and method 2 to the formation of nanocubes (with predominant (100) plane). That is in accordance with other literature findings. For example, it was shown by PèrezRamirez and co-workers ${ }^{39}$ that ceria samples of variable morphologies could be prepared by different methods. Methods based on precipitation often lead to the formation of so-called conventional ceria nanoparticles, while hydrothermal synthesis dominantly leads to the formation of nanocubes (as also shown here). The change in morphology was also confirmed ${ }^{39}$ by the thermal treatment which changes the crystal morphology, leading finally to nanocubes. This actually results in an increase of (100) planes which is in accordance with the findings that the (100) surface is predominantly exposed in nanocubes, while the (111) surface prevails in octahedron-like $\mathrm{CeO}_{2}$ particles. ${ }^{39}$

It is important to state here that the disappearance of the (111) plane depends on its energy. Recently, Amoresi et al. ${ }^{40}$ calculated from DFT the stability of various $\mathrm{CeO}_{2}$ surfaces. They found that energetically the most stable surface is (111) (energy $=1.19 \mathrm{~J} \mathrm{~m}^{-2}$ ) followed by the (110) and (220) surfaces $\left(\right.$ energy $=1.60 \mathrm{~J} \mathrm{~m}^{-2}$ ). The role of the temperature in the kinetics for the generation of NPs is important, not only for the transition states but also for the final surfaces. Amoresi et al. ${ }^{40}$ showed that the energies of the surfaces are not very different, showing that various sites can possibly be created at the interface and that the calculated values present the averages of values obtained for different sites.

3.2. Role of the Surface Charge; Do Experiment and Theory Match? One of the challenges in studying nanoparticles is to reliably determine (experimentally or theoret- 

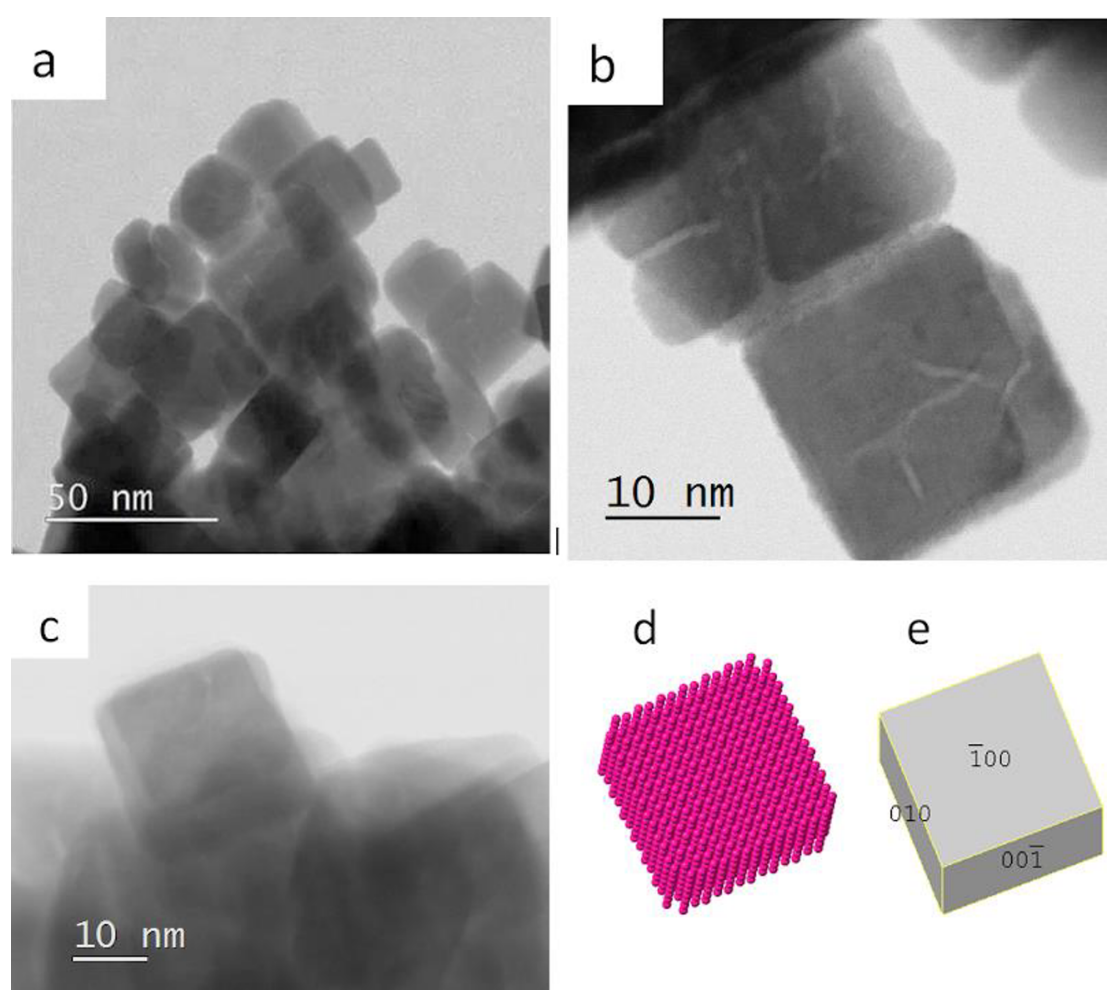

Figure 5. (a, b) STEM-BF images of $\mathrm{CeO}_{2}$ cubic nanoparticles in sample 2. (c) $\mathrm{CeO}_{2}$ nanocube in zone axis between (100) and (110). (d) Crystal model with the position of $\mathrm{Ce}$ atoms ( $\mathrm{O}$ atoms are for clarity not shown). (e) The corresponding model of a cube that can explain the morphology of the particle.

a)

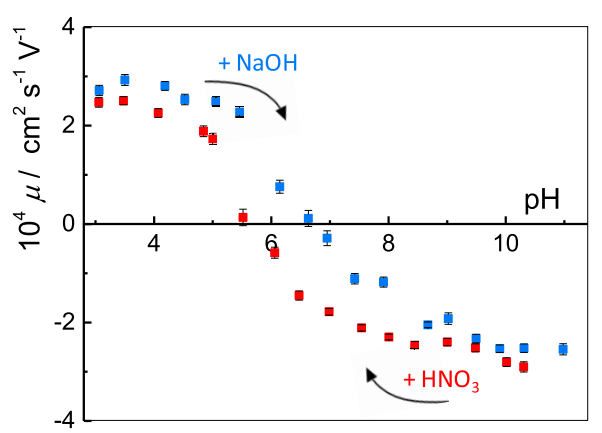

b)

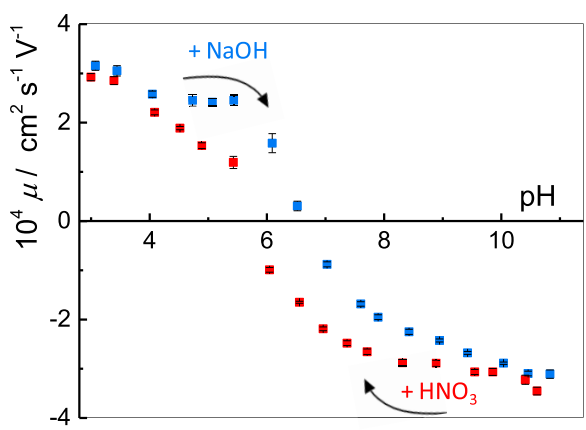

c)

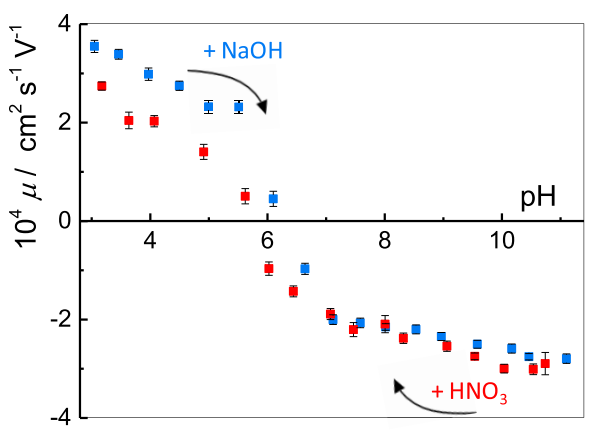

Figure 6. Dependence of electrophoretic mobility of truncated octahedron $\mathrm{CeO}_{2}$ nanoparticles on $\mathrm{pH}$ obtained by the titration of the suspension of $\mathrm{CeO}_{2} \mathrm{NPs}\left(\gamma\left(\mathrm{CeO}_{2}\right)=0.1 \mathrm{~g} \mathrm{dm}^{-3}\right)$ at two different ionic strength values $\left[(\mathrm{a}) I_{\mathrm{c}}=0.002 \mathrm{~mol} \mathrm{dm}^{-3}\right.$ and $\left.(\mathrm{b}) I_{\mathrm{c}}=0.011 \mathrm{~mol} \mathrm{dm}^{-3}\right]$ in the presence of sodium ions and (c) at $I_{\mathrm{c}}=0.011 \mathrm{~mol} \mathrm{dm}{ }^{-3}$ in the presence of cesium ions, $\theta=25{ }^{\circ} \mathrm{C}$. Blue symbols indicate the titration from the acidic to basic region, and red symbols indicate the titration from the basic to acidic region, as also shown by arrows.

ically, ideally both) the surface charge properties. Several experimental methods exist to gain such information such as measurements of the surface charge, surface potential, or zeta potential. From the surface charge density measurements, the point of zero charge $\left(\mathrm{pH}_{\mathrm{pzc}}\right)$ could be obtained, while zeta potential (or electrophoretic mobility) measurements provide 
a)

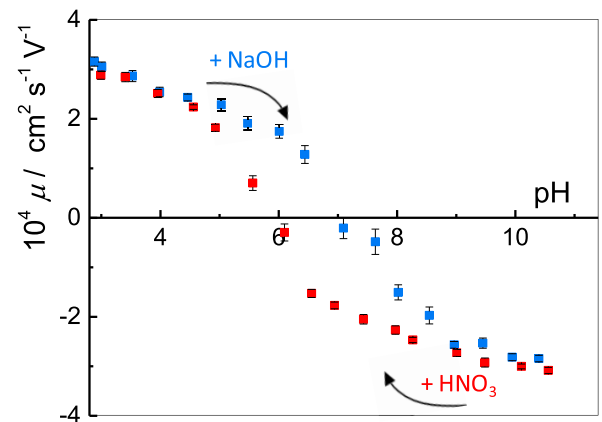

b)

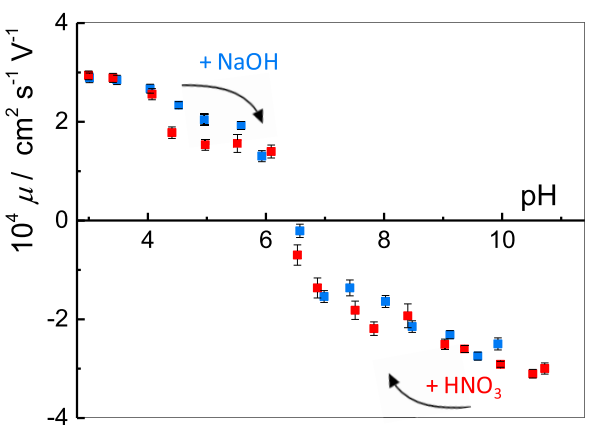

Figure 7. Dependence of electrophoretic mobility of cubic $\mathrm{CeO}_{2}$ nanoparticles on $\mathrm{pH}$ obtained by the titration of the suspension of $\mathrm{CeO} \mathrm{NPs}_{2}$ $\left(\gamma\left(\mathrm{CeO}_{2}\right)=0.1 \mathrm{~g} \mathrm{dm}^{-3}\right)$ in both directions in the presence of sodium ions $(\mathrm{a})$ and in the presence of cesium ions $(\mathrm{b}) ; I_{\mathrm{c}}=0.011 \mathrm{~mol} \mathrm{dm}{ }^{-3}, \theta=25$ ${ }^{\circ} \mathrm{C}$. Blue symbols indicate the titration from the acidic to basic region, and red symbols indicate the titration from the basic to acidic region, as also shown by arrows.

the isoelectric point $\left(\mathrm{pH}_{\mathrm{iep}}\right)$ value, which represents the concentration (activity) of potential determining ions at which the zeta potential equals to zero. Under the surface zero-charge conditions, in the absence of specific ions adsorption, the electrokinetic isoelectric point $\left(\mathrm{pH}_{\text {iep }}\right)$ and the point of zero charge $\left(\mathrm{pH}_{\mathrm{pzc}}\right)$ coincide. On the contrary, in the case of specific adsorption they shift in opposite directions. The exact information about these zero-charge conditions also enables more accurate use of theoretical models.

The measurements of the electrophoretic mobility of nanoparticles are therefore considered as a valuable source of information especially regarding the charging properties of various samples, but also apropos ionic strength and salt-type effects on nanoparticles. The method is based on the analysis of the (laser) light scattered by moving particles. The mobilities are determined from the measured Doppler shift in angular frequency and the applied electric field. In our study we examined the electrophoretic mobility of $\mathrm{CeO}_{2}$ nanoparticles measurements at two ionic strength values $\left(I_{c}=0.002\right.$ and $0.011 \mathrm{~mol} \mathrm{dm}^{-3}$ ) and in the presence of two cations (sodium and cesium). We studied the effect of $\mathrm{pH}$ on electrophoretic mobility of $\mathrm{CeO}_{2} \mathrm{NPs}$ at $\mathrm{CeO}_{2} \mathrm{NP}$ mass concentration of $\gamma=0.1 \mathrm{~g} \mathrm{dm}^{-3}$, and the isoelectric point was estimated from the obtained mobility results.

Results of mobility measurements in ceria suspensions at two different ionic strengths and in the presence of both studied cations are shown in Figure 6. The titrations are performed in both directions in terms of $\mathrm{pH}$; from the acidic to basic region (starting $\mathrm{pH}$ was adjusted with $\mathrm{HNO}_{3}$, and other points were obtained by addition of $\mathrm{NaOH}$ or $\mathrm{CsOH}$ ) and from the basic to acidic region, as indicated by arrows. It is apparent that both curves do not match completely. In other words, the curve that shows titration from basic to acidic is shifted to lower $\mathrm{pH}$ values, resulting in hysteresis. This effect is typical for potentiometric titrations and could be explained on the basis of the kinetics of reactions that are taking place at the surface. As shown in Figure 6, the observed hysteresis was more pronounced in the $\mathrm{pH}$ region close to neutrality than in the acidic and basic $\mathrm{pH}$ region. Therefore, it could be attributed to relatively slow equilibration of surface reactions at the ceria surface at neutral $\mathrm{pH}$ and faster equilibration in acidic and basic environments. ${ }^{41}$ Moreover, although the ionic strength is (almost) constant, the nature of ions in the solutions slightly differs at various $\mathrm{pH}$ values, which could also contribute to the observed hysteresis.
The analysis of the obtained results shown in Figure 6 reveals that the isoelectric point determined from the measurements performed in the presence of sodium ions (for both ionic strengths) is $\mathrm{pH}_{\text {iep }}=6.2 \pm 0.3$. Therefore, no significant influence of ionic strength on the isoelectric point of ceria nanoparticles is observed, at least in the examined conditions. On the other hand, the isoelectric point obtained in the presence of cesium ions is found to be $\mathrm{pH}_{\text {iep }}=6.1 \pm 0.3$. Therefore, a slight cation type effect is noticeable. The obtained results are in accordance with the literature values for ceria nanoparticles. ${ }^{42}$ In all examined cases the isoelectric point was determined from titrations in both directions, and the final result was presented as the mean value of both measurements. No significant difference in the obtained results has been noticed, except in the cesium suspensions where mobility values were more systematic (less deviation from the curve); in other words, the error of $\mathrm{pH}_{\text {iep }}$ is lower. It should be noted here that the scattering of the data on the isoelectric points of various metal oxides ${ }^{42}$ might be partially explained by hysteresis.

As in the case for the nanoparticles prepared by method 1 , the isoelectric point of the nanoparticles prepared by method 2 was also determined by titrations in both directions, as indicated by arrows. The ionic strength was adjusted with sodium or cesium nitrate as well as with nitric acid or sodium/ cesium hydroxide $\left(I_{c}=0.011 \mathrm{~mol} \mathrm{dm}^{-3}\right)$.

From the results presented in Figure 7 , it is possible to compare the mobilities and the corresponding isoelectric points in the presence of sodium and cesium ions. The obtained results are again not significantly different. The estimated isoelectric point of ceria nanoparticles in the presence of sodium ions is $\mathrm{pH}_{\text {iep }}=6.5 \pm 0.5$ and in the presence of cesium ions is $\mathrm{pH}_{\text {iep }}=6.4 \pm 0.1$. It seems that the hysteresis is less pronounced in the presence of cesium ions.

Surface charge density $(\sigma)$ measurements are also considered extremely valuable in the process of characterization of various types of nanoparticles. There are several experimental methods that could be used for that purpose. The main tool commonly used for the determination of surface charge densities of metal oxides, the charge of which depends on the activities of potential determining $\mathrm{H}^{+}$and $\mathrm{OH}^{-}$ions, is potentiometric titration of the suspension. ${ }^{43}$ Additionally, mass titration originally developed by $\mathrm{Noh}$ and Schwarz ${ }^{44}$ as a method for determination of the point of zero charge $\left(\mathrm{pH}_{\mathrm{pzc}}\right)$ of pure metal oxides (in the absence of acidic or basic impurities) and extended later by Žalac and Kallay ${ }^{45}$ for 
determination of the point of zero charge of contaminated samples is one of the often used methods. However, in our study we decided to apply polyelectrolyte titration with streaming potential measurement (colloid titration) which was accepted as a method of choice for the surface charge density determination of various types of colloid particles that differ in the size and shape. ${ }^{32,46}$ There are several advantages of the polyelectrolyte titration over other more conventional methods. One of them lies in the simplicity of conducting the experiment which is monitoring a response of the streaming potential as a function of the added titrant volume. A standardized aqueous solution of a strong polyelectrolyte serves as titrant, and the end point corresponds to compensation of a total charge of investigated (nano)particles. Irrespective of the structure of the titrated particle, the polyelectrolyte binds to the surface and compensates for the charge. Finally, measurements of surface charge density enable the determination of the point of zero charge $\left(\mathrm{pH}_{\mathrm{pzc}}\right)$.

Therefore, we performed a polyelectrolyte titration of the suspension of truncated octahedron $\mathrm{CeO}_{2} \mathrm{NPs}$. Evidence for the full functionalization of ceria surface with oppositely charged polyelectrolytes is shown in Figure $8 \mathrm{~A}$ where the

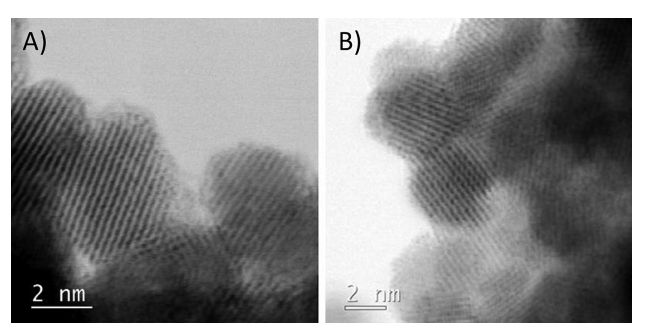

Figure 8. (A) HR-TEM micrographs of ceria nanoparticles coated with poly(sodium 4-styrenesulfonate) at $\mathrm{pH}=2$. (B) HR-TEM micrographs of bare $\mathrm{CeO}_{2} \mathrm{NPs}$ at $\mathrm{pH}=10$.

polyelectrolyte-coated cerium oxide nanoparticles are shown. Namely, at $\mathrm{pH}=2$ the strong polyanion poly(sodium 4styrenesulfonate), PSS, is negatively charged whereas $\mathrm{CeO}_{2}$ NPs are positively charged, and there is strong electrostatic attraction. We observed a ca. $2 \mathrm{~nm}$ thick layer of organic material with different contrast than the $\mathrm{CeO}_{2} \mathrm{NP}$ material. On the other hand, nonfunctionalized $\mathrm{CeO}_{2} \mathrm{NPs}$ form a clear and flat boundary with the air phase (Figure $8 \mathrm{~B}$ ) because at $\mathrm{pH}=$ 10 there is a strong electrostatic repulsion between the negatively charged PSS and $\mathrm{CeO}_{2}$ NPs. Herewith, it was confirmed again that HR-TEM is a powerful method which could be successfully applied for monitoring polyelectrolyte adsorption on nanoparticles.

From the functionalization of $\mathrm{CeO}_{2} \mathrm{NP}$ surfaces with polyelectrolytes using Mutek-PCD05, we determined the surface charge density of $\mathrm{CeO}_{2}$ NPs. The results of polyelectrolyte titrations are shown in Figure 9, where the surface charge density of $\mathrm{CeO}_{2} \mathrm{NPs}$ as a function of $\mathrm{pH}$ is given.

From the experimental results presented in Figure 9 it could be concluded that the value of the point of zero charge of truncated octahedron $\mathrm{CeO}_{2} \mathrm{NPs}$ is $\mathrm{pH}_{\mathrm{pzc}}=6.0$ (for $I_{\mathrm{c}}=2 \times$ $\left.10^{-3} \mathrm{~mol} \mathrm{dm}^{-3}\right)$. The difference in the values of the isoelectric point (from mobility measurements, Figure 6) and of the point of zero charge is the consequence of the specific adsorption of ions. Moreover, from the obtained HR-TEM images of the truncated octahedron $\mathrm{CeO}_{2} \mathrm{NPs}$ (Figure 3), we concluded

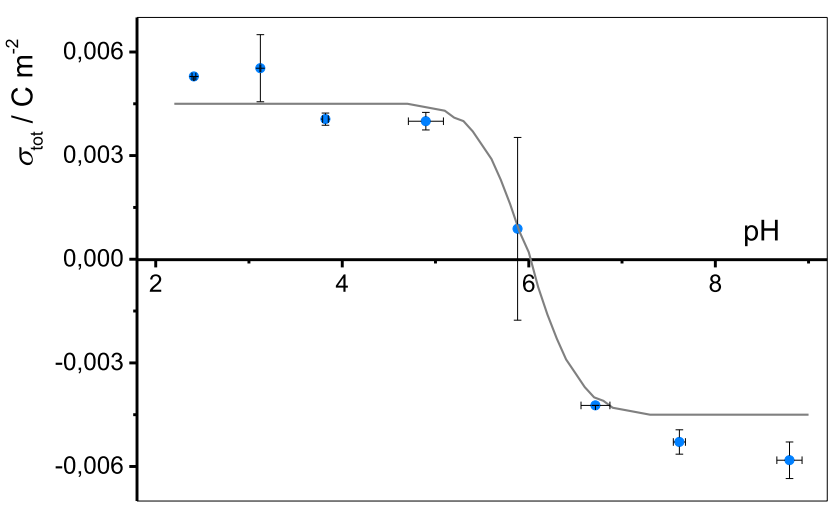

Figure 9. Comparison of the experimentally obtained dependence of surface charge density of truncated octahedron $\mathrm{CeO}_{2} \mathrm{NPs}$ on $\mathrm{pH}$ (blue dots) with the results obtained by the density functional theory (gray line) $I_{\mathrm{c}}=2 \times 10^{-3} \mathrm{~mol} \mathrm{dm}{ }^{-3}$ and $\gamma=0.1 \mathrm{~g} \mathrm{dm}^{-3}$.

that the size of $\mathrm{CeO}_{2} \mathrm{NP}$ is around $4 \mathrm{~nm}$. A clear crystallinity state of $\mathrm{CeO}_{2}$ with negligible amorphous part is indicated. This fact allows us to define two reactions responsible for the charging of $\mathrm{CeO}_{2}$ NPs surfaces:

$$
\begin{gathered}
\equiv \mathrm{Ce}_{2} \mathrm{O}^{-}+\mathrm{H}^{+} \leftrightarrow \equiv \mathrm{Ce}_{2} \mathrm{OH}^{0} \\
\equiv \mathrm{Ce}_{2} \mathrm{OH}^{0}+\mathrm{H}^{+} \leftrightarrow \equiv \mathrm{Ce}_{2} \mathrm{OH}_{2}^{+}
\end{gathered}
$$

with the corresponding equilibrium constants $K_{1}$ and $K_{2}$

$$
K_{1}=\frac{\left[\mathrm{Ce}_{2} \mathrm{OH}^{0}\right]}{\left[\mathrm{Ce}_{2} \mathrm{O}^{-}\right]\left[\mathrm{H}^{+}\right]}, \quad K_{2}=\frac{\left[\mathrm{Ce}_{2} \mathrm{OH}_{2}^{+}\right]}{\left[\mathrm{Ce}_{2} \mathrm{OH}^{0}\right]\left[\mathrm{H}^{+}\right]}
$$

Our HR-TEM results (Figure 3) revealed that the ceria nanocrystals are bordered to the air phase mainly by the (111) and (100) planes. By immersion in the solution, these planes are exposed to the electrolyte solution and contribute to the overall surface charge which was measured in our polyelectrolyte titration experiments. Therefore, it should be noted that 2 - $\mathrm{pK}$ model we used to construct our theory is an approximation in which one kind of amphoteric surface site is assumed at the ceria surface. With this approximation it makes sense to compare the theory with experiments in which average surface properties are measured.

For a better understanding and improved interpretation of the surface charge density dependence on $\mathrm{pH}$, we prepared a theoretical model based on the classical density functional theory for electrolyte solutions coupled with the surface charge regulation via the law of mass action. The details are given in the Experimental Section and in the Supporting Information.

As seen from Figure 9, the theory can adequately describe the experimental data. What is especially beautiful is that there are no fitting parameters in the theory. The product of both reaction constants is determined from the $\mathrm{pH}_{\mathrm{pzc}}$ at the point of zero charge $\left(\mathrm{pH}_{\mathrm{pzc}}=6\right)$. This value was taken from surface charge measurements (see Figure 9). The surface site density $\Gamma$ was determined from the surface charge density at lower $\mathrm{pH}$ values and is equal to 0.13 site $/ \mathrm{nm}^{2}$. The model can quantitatively describe the titration curve as a function of $\mathrm{pH}$.

\section{CONCLUSIONS}

We synthesized and fully characterized, experimentally and theoretically, two types of $\mathrm{CeO}_{2} \mathrm{NPs}$ (truncated octahedron and cubic ceria nanoparticles). For that purpose, we applied the holistic approach that combines experimental and 
theoretical studies. A systematic experimental investigation enabled us to find out the exact morphology of the investigated $\mathrm{CeO}_{2}$ NPs. Surface charge and mobility measurements allowed us to determine the charging properties of the studied nanoparticles as well as the ionic strength and cation type effect which was not found to be significant. This systematic approach has allowed us to continue with the theoretical approach for which experimentally obtained properties of $\mathrm{CeO}_{2}$ NPS (e.g., shape, planes, and point of zero charge) are needed. Special emphasis was given to the determination of neutrality points of $\mathrm{CeO}_{2} \mathrm{NPs}$ (isoelectric point and point of zero charge). It is worth mentioning here that in the case of electrokinetic mobility measurements the hysteresis was observed in the $\mathrm{pH}$ region close to neutrality. The effect of hysteresis could also possibly explain the scattering of the data on the isoelectric points of various metal oxides found in the literature.

To get a more complete picture of the system, we prepared also a theoretical model based on the classical density functional theory for electrolyte solutions coupled with the surface charge regulation via the law of mass action. Our theory can reproduce the experimental results even without fitting parameters. Such an approach that combines experiment and theory contributes to a deeper understanding of the studied system. To sum up, our results provide a framework for tuned applications, especially in the field of biomedicine, which could lead to obtaining engineered ceria nanoparticles with optimized physicochemical properties.

\section{ASSOCIATED CONTENT}

\section{SI Supporting Information}

The Supporting Information is available free of charge at https://pubs.acs.org/doi/10.1021/acsanm.0c02960.

Detailed description and illustration of the applied theoretical model; additional HR-TEM images of truncated octahedron and cubic ceria nanoparticles; and BF-STEM micrographs and EELS spectra of truncated octahedron and cubic ceria nanoparticles (PDF)

\section{AUTHOR INFORMATION}

\section{Corresponding Authors}

Davor Kovačević - Department of Chemistry, Faculty of

Science, University of Zagreb, 10000 Zagreb, Croatia;

(1) orcid.org/0000-0001-6446-3459;

Email: davor.kovacevic@chem.pmf.hr

Klemen Bohinc - Faculty of Health Sciences, University of Ljubljana, SI-1000 Ljubljana, Slovenia; (ㄱ) orcid.org/00000003-2126-8762; Email: klemen.bohinc@zf.uni-lj.si

\section{Authors}

Karla Korade - Department of Chemistry, Faculty of Science, University of Zagreb, 10000 Zagreb, Croatia

Katarina Jerin - Department of Chemistry, Faculty of Science, University of Zagreb, 10000 Zagreb, Croatia

Nikolina Lešic - Department of Chemistry, Faculty of Science, University of Zagreb, 10000 Zagreb, Croatia

Marijana Đaković - Department of Chemistry, Faculty of Science, University of Zagreb, 10000 Zagreb, Croatia; (1) orcid.org/0000-0001-6789-6399

Goran Dražić - Department for Materials Chemistry, National Institute of Chemistry, SI-1000 Ljubljana, Slovenia
Jean-François Dufrêche - Institut de Chimie Séparative de Marcoule (ICSM), UMR 5257, CEA, CNRS, ENSCM, Université de Montpellier, F-30207 Bagnols-sur-Ceze, France

Complete contact information is available at:

https://pubs.acs.org/10.1021/acsanm.0c02960

\section{Notes}

The authors declare no competing financial interest.

\section{ACKNOWLEDGMENTS}

K.B. thanks the Slovenian Research Agency for support through program P3-0388. K.B. and D.K. thank the Slovenian Research Agency for the financial support through project J72595 and the Croatian Science Foundation for the financial support through project IPS-2020-01-6126. Results presented in this publication were partially obtained in the framework of the CEEPUS network Colloids and nanomaterials in education and research. The authors are thankful to Branka Njegic Džakula for BET analysis and Danijel Namjesnik for technical assistance.

\section{REFERENCES}

(1) Das, S.; Dowding, J. M.; Klump, K. E.; McGinnis, J. F.; Self, W.; Seal, S. Cerium Oxide Nanoparticles: Applications and Prospects in Nanomedicine. Nanomedicine 2013, 8 (9), 1483-1508.

(2) Dahle, J. T.; Arai, Y. Environmental geochemistry of cerium: applications and toxicology of cerium oxide nanoparticles. Int. J. Environ. Res. Public Health 2015, 12, 1253-1278.

(3) Yang, C.; Yu, X.; Heißler, S.; Weidler, P. G.; Nefedov, A.; Wang, Y.; Wöll, C.; Kropp, T.; Paier, J.; Sauer, J. $\mathrm{O}_{2}$ activation on ceria catalysts - the importance of substrate crystallographic orientation. Angew. Chem., Int. Ed. 2017, 56 (51), 16399-16404.

(4) Pirmohamed, T.; Dowding, J. M.; Singh, S.; Wasserman, B.; Heckert, E.; Karakoti, A. S.; King, J. E. S.; Seal, S.; Self, W. T. Nanoceria exhibit redox state-dependent catalase mimetic activity. Chem. Commun. 2010, 46 (16), 2736-2738.

(5) Deshpande, S.; Patil, S.; Kuchibhatla, S. V.; Seal, S. Size dependency variation in lattice parameter and valency states in nanocrystalline cerium oxide. Appl. Phys. Lett. 2005, 87 (13), 133113.

(6) Yang, C.; Yu, X.; Heißler, S.; Nefedov, A.; Colussi, S.; Llorca, J.; Trovarelli, A.; Wang, Y.; Wöll, C. Surface faceting and reconstruction of ceria nanoparticles. Angew. Chem., Int. Ed. 2017, 56 (1), 375-379.

(7) Thakur, N.; Manna, P.; Das, J. Synthesis and biomedical applications of nanoceria, a redox active nanoparticle. J. Nanobiotechnol. 2019, 17 (1), No. 84.

(8) Huang, X.; Li, L.-D.; Lyu, G.-M.; Shen, B.-Y.; Han, Y.-F.; Shi, J.L.; Teng, J.-L.; Feng, L.; Si, S.-Y.; Wu, J.-H.; Liu, Y.-J.; Sun, L.-D.; Yan, C.-H. Chitosan-coated cerium oxide nanocubes accelerate cutaneous wound healing by curtailing persistent inflammation. Inorg. Chem. Front. 2018, 5, 386-393.

(9) Choi, S. W.; Kim, J. Recent Progress in Autocatalytic Ceria Nanoparticles-Based Translational Research on Brain Diseases. ACS Applied Nano Materials 2020, 3, 1043-1062.

(10) Allawadhi, P.; Khurana, A.; Allwadhi, S.; Joshi, K.; Packirisamy, G.; Bharani, K. K. Nanoceria as a possible agent for the management of COVID-19. Nano Today 2020, 35, No. 100982.

(11) Kim, I.-S.; Baek, M.; Choi, S.-J. Comparative cytotoxicity of $\mathrm{Al}_{2} \mathrm{O}_{3}, \mathrm{CeO}_{2}, \mathrm{TiO}_{2}$ and $\mathrm{ZnO}$ nanoparticles to human lung cells. $J$. Nanosci. Nanotechnol. 2010, 10 (5), 3453-3458.

(12) Gojova, A.; Lee, J.-T.; Jung, H. S.; Guo, B.; Barakat, A. I.; Kennedy, I. M. Effect of cerium oxide nanoparticles on inflammation in vascular endothelial cells. Inhalation Toxicol. 2009, 21, 123-130.

(13) Preaubert, L.; Courbiere, B.; Achard, V.; Tassistro, V.; Greco, F.; Orsiere, T.; Bottero, J.-Y.; Rose, J.; Auffan, M.; Perrin, J. Cerium dioxide nanoparticles affect in vitro fertilization in mice. Nanotoxicology 2016, 10 (1), 111-117. 
(14) Préaubert, L.; Tassistro, V.; Auffan, M.; Sari-Minodier, I.; Rose, J.; Courbiere, B.; Perrin, J. Very low concentration of cerium dioxide nanoparticles induce DNA damage, but no loss of vitality, in human spermatozoa. Toxicol. In Vitro 2018, 50, 236-241.

(15) Pulido-Reyes, G.; Rodea-Palomares, I.; Das, S.; Sakthivel, T. S.; Leganes, F.; Rosal, R.; Seal, S.; Fernández-Piñas, F. Untangling the biological effects of cerium oxide nanoparticles: the role of surface valence states. Sci. Rep. 2015, 5, 15613.

(16) Shah, V.; Shah, S.; Shah, H.; Rispoli, F. J.; McDonnell, K. T.; Workeneh, S.; Karakoti, A.; Kumar, A.; Seal, S. Antibacterial activity of polymer coated cerium oxide nanoparticles. PLoS One 2012, 7 (10), e47827.

(17) Pelletier, D. A.; Suresh, A. K.; Holton, G. A.; McKeown, C. K.; Wang, W.; Gu, B.; Mortensen, N. P.; Allison, D. P.; Joy, D. C.; Allison, M. R.; Brown, S. D.; Phelps, T. J.; Doktycz, M. J. Effects of engineered cerium oxide nanoparticles on bacterial growth and viability. Appl. Environ. Microbiol. 2010, 76 (24), 7981-7989.

(18) Fang, X.; Yu, R.; Li, B.; Somasundaran, P.; Chandran, K. Stresses exerted by $\mathrm{ZnO}, \mathrm{CeO}_{2}$ and anatase $\mathrm{TiO}_{2} \mathrm{NPs}$ on the Nitrosomonas europaea. J. Colloid Interface Sci. 2010, 348 (2), 329334.

(19) Sun, C.; Xue, D. Size-dependent oxygen storage ability of nanosized ceria. Phys. Chem. Chem. Phys. 2013, 15, 14414-14419.

(20) Trenque, I.; Magnano, G. C.; Bolzinger, M. A.; Roiban, L.; Chaput, F.; Pitault, I.; Briançon, S.; Devers, T.; Masenelli-Varlot, K.; Bugnet, M.; Amans, D. Shape-selective synthesis of nanoceria for degradation of paraoxon as chemical warfare simulant. Phys. Chem. Chem. Phys. 2019, 21 (10), 5455-5465.

(21) Brkljača, Z.; Lešić, N.; Bertović, K.; Dražić, G.; Bohinc, K.; Kovačević, D. Polyelectrolyte-coated Cerium Oxide Nanoparticles: Insights into Adsorption Process. J. Phys. Chem. C 2018, 122 (48), 27323-27330.

(22) Santiago, A. A. G.; Oliveira, M. C.; Ribeiro, R. A. P.; Tranquilin, R. L.; Longo, E.; de Lázaro, S. R.; Motta, F. V.; Bomio, M. R. D. Atomistic Perspective on the Intrinsic White-Light Photoluminescence of Rare-Earth Free $\mathrm{MgMoO}_{4}$ Nanoparticles. Cryst. Growth Des. 2020, 20 (10), 6592-6603.

(23) Santiago, A. A. G.; Tranquilin, R. L.; Oliveira, M. C.; Ribeiro, R. A. P.; de Lazaro, S. R.; Correa, M. A.; Bohn, F.; Longo, E.; Motta, F. V.; Bomio, M. R. D. Disclosing the Structural, Electronic, Magnetic, and Morphological Properties of $\mathrm{CuMnO}_{2}$ : A Unified Experimental and Theoretical Approach. J. Phys. Chem. C 2020, 124 (9), 53785388.

(24) Ribeiro, R. A. P.; Oliveira, M. C.; Bomio, M. R. D.; de Lazaro, S. R.; Andrés, J.; Longo, E. Connecting the surface structure, morphology and photocatalytic activity of Ag2O: An in depth and unified theoretical investigation. Appl. Surf. Sci. 2020, 509, 145321.

(25) Ribeiro, R. A. P.; de Lazaro, S. R.; Gracia, L.; Longo, E.; Andrés, J. Theoretical approach for determining the relation between the morphology and surface magnetism of $\mathrm{Co}_{3} \mathrm{O}_{4}$. J. Magn. Magn. Mater. 2018, 453, 262-267.

(26) Mourdikoudis, S.; Pallares, R. M.; Thanh, N. T. K. Characterization techniques for nanoparticles: comparison and complementarity upon studying nanoparticle properties. Nanoscale 2018, 10, 12871-12934.

(27) Namjesnik, D.; Mutka, S.; Iveković, D.; Gajović, A.; Willinger, M.; Preočanin, T. Application of the surface potential data to elucidate interfacial equilibrium at ceria/aqueous electrolyte interface. Adsorption 2016, 22, 825-837.

(28) Merai, L.; Janovak, L.; Kovacs, D. S.; Szenti, I.; Vasarhelyi, L.; Kukovecz, A.; Dekany, I.; Konya, Z.; Sebok, D. Fast optical method for characterizing plasmonic nanoparticle adhesion on functionalized surfaces. Anal. Bioanal. Chem. 2020, 412, 3395-3404.

(29) Bohinc, K.; Bossa, G. V.; May, S. Incorporation of ion and solvent structure into mean-field modeling of the electric double layer. Adv. Colloid Interface Sci. 2017, 249, 220-233.

(30) Ben-Yaakov, D.; Andelman, D.; Podgornik, R.; Harries, D. Ionspecific hydration effects: Extending the Poisson-Boltzmann theory. Curr. Opin. Colloid Interface Sci. 2011, 16, 542-550.
(31) Ninham, B. W.; Persegian, V. A. Electrostatic potential between surfaces bearing ionizable groups in ionic equilibrium with physiologic saline solution. J. Theor. Biol. 1971, 31 (3), 405-428.

(32) Špadina, M.; Gourdin-Bertin, S.; Dražić, G.; Selmani, A.; Dufreche, J. F.; Bohinc, K. Charge properties of $\mathrm{TiO}_{2}$ nanotubes in $\mathrm{NaNO}_{3}$ aqueous solution. ACS Appl. Mater. Interfaces 2018, 10 (15), 13130-13142.

(33) Zhang, F.; Chan, S. W.; Spanier, J. E.; Apak, E.; Jin, Q.; Robinson, R. D.; Herman, I. P. Cerium oxide nanoparticles: Sizeselective formation and structure analysis. Appl. Phys. Lett. 2002, 80 (1), 127-129.

(34) Siboulet, B.; Hocine, S.; Hartkamp, R.; Dufrêche, J.-F. Scrutinizing Electro-Osmosis and Surface Conductivity with Molecular Dynamics. J. Phys. Chem. C 2017, 121, 6756-6769.

(35) Schwierz, N.; Horinek, D.; Sivan, U.; Netz, R. R. Reversed Hofmeister series - The rule rather than the exception. Curr. Opin. Colloid Interface Sci. 2016, 23, 10-18.

(36) Langford, J. I.; Wilson, A. J. C. Scherrer after sixty years: A survey and some new results in the determination of crystallite size. J. Appl. Crystallogr. 1978, 11, 102-113.

(37) Monshi, A.; Foroughi, M. R.; Monshi, M. R. Modified Scherrer equation to estimate more accurately nano-crystallite size using XRD. World J. Nano Sci. Eng. 2012, 2 (3), 154-160.

(38) X'Pert High Score Plus Package; Panalytical B. V.: Almelo, The Netherlands, 2003.

(39) Vilè, G.; Colussi, S.; Krumeich, F.; Trovarelli, A.; PèrezRamirez, J. Opposite Face Sensitivity of $\mathrm{CeO}_{2}$ in Hydrogenation and Oxidation Catalysis. Angew. Chem., Int. Ed. 2014, 53, 12069-12072.

(40) Amoresi, R. A. C.; Oliveira, R. C.; Marana, N. L.; de Almeida, P. B.; Prata, P. S.; Zaghete, M. A.; Longo, E.; Sambrano, J. R.; Simões, A. Z. $\mathrm{CeO}_{2}$ Nanoparticle Morphologies and Their Corresponding Crystalline Planes for the Photocatalytic Degradation of Organic Pollutants. ACS Appl. Nano Mater. 2019, 2 (10), 6513-6526.

(41) Preočanin, T.; Cop, A.; Kallay, N. Surface potential of hematite in aqueous electrolyte solution: Hysteresis and equilibration at the interface. J. Colloid Interface Sci. 2006, 299 (2), 772-776.

(42) Kosmulski, M. Surface Charging and Points of Zero Charge; Surfactant Science Series; CRC Press: Boca Raton, FL, 2009.

(43) Lützenkirchen, J.; Preočanin, T.; Kovačević, D.; Tomišić, V.; Lövgren, L.; Kallay, N. Potentiometric Titrations as a Tool for Surface Charge Determination. Croat. Chem. Acta 2012, 85 (4), 391-417.

(44) Noh, J. S.; Schwarz, J. A. Estimation of the point of zero charge of simple oxides by mass titration. J. Colloid Interface Sci. 1989, 130 (1), 157-164.

(45) Žalac, S.; Kallay, N. Application of Mass Titration to the Point of Zero Charge Determination. J. Colloid Interface Sci. 1992, 149 (1), 233-240.

(46) Grover, I. S.; Singh, S.; Pal, B. The preparation, surface structure, zeta potential, surface charge density and photocatalytic activity of $\mathrm{TiO}_{2}$ nanostructures of different shapes. Appl. Surf. Sci. 2013, 280, 366-372. 